\title{
Q ualidade da madeira de cinco espécies florestais para o envelhecimento da cachaça ${ }^{1}$
}

\author{
Catarina G. Catão², Juarez B. Paes ${ }^{3}$, Josivanda P. G omes \& \& Gilmar T. Araújo ${ }^{4}$
}

\begin{abstract}
RESU MO
Realizou-se esta pesquisa com o objetivo de avaliar as características das madeiras de amburana (Amburana cearencis (Fr. Allem.) A.C. Sm.), bálsamo (M yroxylon peruiferum L.f.), ipê-amarelo (Tabebuia chrysotricha (Mart. ex DC.) Standl.), jatobá (Hymenaea courbaril L. var. stilbocarpa (Hayne) Lee et Lang.) e jequitibá-rosa (Cariniana legalis (M art.) Kuntze) no armazenamento de cachaças; comparar as cachaças com amostra armazenada em barril de carvalho (Q uercus sp.), analisar o efeito do envelhecimento e comparar os valores obtidos com os padronizados pela Legislação Brasileira. Para tanto, as cachaças foram armazenadas em barris de madeira e em recipiente de vidro e analisadas suas características químicas (acidez volátil, álcool metílico, álcool superior, aldeído, cobre, éster, extrato seco a 100 으, furfural e grau alcoólico) e organolépticas (cor, sabor e aroma). Após seis meses de armazenamento as cachaças foram comparadas com os valores padronizados. Independente da espécie, a madeira melhorou as qualidades sensoriais da cachaça incorporando, à bebida, cor, gosto e sabor característicos. Todas as cachaças avaliadas continuaram dentro dos padrões de qualidade estabelecidos pela Legislação Brasileira.
\end{abstract}

Palavras-chave: armazenamento, aguardente, características químicas, características organolépticas

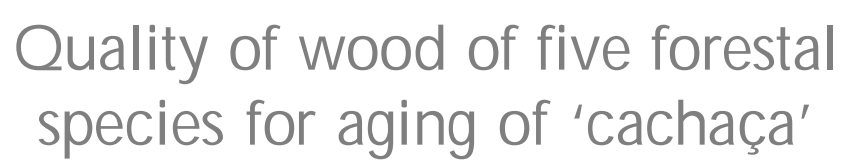

ABSTRACT

This research aimed to evaluate the wood quality of Amburana cearencis (Fr. Allem.) A.C. Sm., Myroxylon peruiferum L.f., Tabebuia chrysotricha (M art. ex DC.) Standl., H ymenaea courbaril L. var. stilbocarpa (Hayne) Lee et Lang. and Cariniana legalis (Mart.) Kuntze in the storage of "cachaça" (Brazilian sugar cane spirit); to compare the "cachaça" studied with the stored one in barrel of oak (Quercus sp.), to analyze the effect of the aging and to compare the values obtained with the standard ones for the Brazilian Legislation. Thus, the "cachaças" were stored in wooden and glass barrels and their chemical (volatile acidity, methyl alcohol, superior alcohol, aldehyde, cupper, ester, dry extract to $100 \stackrel{\circ}{ }$, furfural contents and alcoholic degree) and organoleptic (color, flavor and aroma) characteristics were analysed. After six months of storage the "cachaças" were compared with the standard values according to Brazilian Legislation. Independent of the species, the wood improves the sensorial qualities of "cachaça", incorporating the drink taste, color and characteristic flavor. All "cachaças" evaluated continued to be with in the standards of quality established by Brazilian Legislation.

Key words: storage, firewater, chemistry characteristics, organoleptics characteristics

Parte da Dissertação de Mestrado do primeiro autor

Q MSW 05 Lote 07 Bloco D, CEP 70680-500, Brasília, DF. Fone: (61) 3033-6828. E-mail: catarina@catarinacatao.com

Departamento de Engenharia Florestal/U FES, Caixa Postal 16, CEP 29550-000, Jerônimo Monteiro, ES. Fone: (28) 3558-2514. E-mail: Jbp2@uol.com.br

4 U AEA e UAEQ/U FCG, Av. Aprígio Veloso 882, Bodocongó, CEP 58429-140, Campina Grande PB. Fone: (83) 2101-1185 e $2101-1115$ R. 23. E-mail: josi@deag.ufcg.edu.br e gilmar@deq.ufcg.edu.br 


\section{INTRODUÇÃO}

Produzida praticamente em todo o Brasil, a cachaça, bebida genuinamente nacional é, atualmente, segundo dados da ABRABE (2005), a terceira bebida destilada mais consumida no mundo e a primeira no Brasil.

Devem-se iniciar os cuidados com a produção da cachaça desde a colheita da cana até a destilação, visto que de um processo bem conduzido se obtém um produto que atenda às especificações legais; mesmo assim, a bebida permanece sensorialmente passível de rejeição, em função da presença de substâncias de odor e sabores desagradáveis, em decorrência do pouco tempo para descanso. Assim, o processo de envelhecimento em barris de madeira é uma das etapas mais significativas do processo, para agregação de valor e qualidade sensorial à cachaça (Moraes, 2001; Miranda et al., 2008; Alcarde et al., 2010).

Durante o envelhecimento ocorrem reações químicas que geram ácidos e aldeídos aromáticos, cor e leve decréscimo no teor alcoólico. A madeira dos tonéis contribui, qualitativa e quantitativamente, com substâncias adicionadas à bebida, variando de acordo com o tipo de madeira e com as substâncias químicas nelas contidas, tornando a cachaça mais suave e agradável (Alcarde et al., 2010), diferente do produto recémdestilado, que apresenta gosto ardente e seco (Padovan et al., 2004; Castro Neto et al., 2005).

Os resultados de vários estudos sensoriais demonstram que cachaças envelhecidas são preferidas pelos consumidores, quando comparadas com cachaças comerciais nãoenvelhecidas e mesmo das comerciais envelhecidas que podem, ainda, receber uma parte de aguardente não-envelhecida e também ter correção da cor por meio da adição de corante e caramelo, conforme permite a Legislação Brasileira (Cardello \& Faria, 2000).

No Brasil colonial, por influência do conhaque, uísque e vinho, os produtores de cachaça passaram a utilizar a madeira de carvalho (Quercus sp.) para envelhecer a bebida permanecendo, até hoje, a tradição da sua utilização, em barris previamente usados em países como Estados Unidos e Escócia, em função do aroma e do sabor, legados pela madeira à cachaça (Miranda et al., 2008; Alcarde et al., 2010).

Apesar do aumento do consumo, da exportação e, consequentemente, da produção da cachaça, a cadeia produtiva no país não é tecnologicamente homogênea, carecendo de estudos e aprimoramentos (Barboza et al., 2010), a fim de ampliar a conquista e a afirmação no mercado internacional.

Outro fator que merece destaque está ligado aos barris de carvalho reutilizados, oriundos de outros países os quais, além de terem alto custo, deixam de lado a utilização da rica flora brasileira (Mori et al., 2003; Alcarde et al., 2010), o que deixaria a bebida mais peculiar, característica e com valor agregado totalmente nacional.

Existe um aumento de mercado da cachaça e procura por bebidas cada vez mais requintadas com sabores, cores e aromas peculiares. O Brasil, grande produtor do destilado, possui uma vasta flora com grande variedade de espécies de madeira com viabilidade de uso para a confecção de barris visando ao envelhecimento de cachaça (Mori et al., 2003), que deve ser estudada e explorada como fator contribuinte para a melhora deste nicho de mercado nacional.

Algumas espécies da flora brasileira já passaram por estudos e se observaram que a composição química e os aspectos físicos da madeira, as ressaltam como possibilidade para uso no armazenamento (envelhecimento) da cachaça (Mori et al., 2003; Alcarde et al., 2010); no entanto, são necessários estudos mais aprofundados a fim de que se encontrem madeiras com composição de extratos capaz de conferir boa qualidade à bebida.

Esta pesquisa teve como objetivo: avaliar as características das madeiras de amburana (Amburana cearencis), bálsamo (Myroxylon peruiferum), ipê-amarelo (Tabebuia chrysotricha), jatobá (Hymenaea courbaril var. stilbocarpa) e jequitibárosa (Cariniana legalis) no armazenamento de cachaças; comparar as cachaças com amostra armazenada em barril de carvalho (Quercus sp.); analisar o efeito do envelhecimento e comparar os valores obtidos com os padronizados pela Legislação Brasileira.

\section{Material e MÉTOdos}

\section{Procedência da cachaça e madeiras utilizadas noenvelhecimento}

Para o desenvolvimento da pesquisa foram empregados 260 L de cachaça com graduação alcoólica de aproximadamente $43^{\circ} \mathrm{GL}$, provenientes de uma destilação de $300 \mathrm{~L}$, realizada em setembro de 2008, no Município de Salinas, localizado no Norte do Estado de Minas Gerais.

Em função de algumas características como diâmetro, comprimento de tronco, densidade, retratibilidade e facilidade de aquisição, utilizaram-se as madeiras de amburana (Amburana cearencis (Fr. Allem.) A.C. Sm.), bálsamo (Myroxylon peruiferum L.f.), ipê-amarelo (Tabebuia Chrysotricha (Mart. ex DC.) Standl.), jatobá (Hymenaea courbaril L. var. Stilbocarpa (Hayne) Lee et Lang.) e jequitibá-rosa (Cariniana legalis (Mart.) Kuntze).

Como comparação entre a qualidade das madeiras empregadas foi usada a madeira de carvalho (Quercus sp.), comumente utilizada para envelhecimento de cachaça e outras bebidas destiladas, sendo bastante aceita pelos apreciadores de bebida.

\section{Confecção e características dos barris utilizados}

Os barris confeccionados para o experimento foram verticais, com $30 \mathrm{~cm}$ de diâmetro e $45 \mathrm{~cm}$ de altura, com capacidade interna de aproximadamente $25 \mathrm{~L}$. Os barris produzidos com as madeiras nacionais foram confeccionados em tábuas nunca antes utilizadas para armazenamento de cachaça, enquanto os de carvalho foram constituídos a partir de pranchas recuperadas de barris importados, que já haviam sido utilizadas para o armazenamento de bebidas alcoólicas.

O processo de confecção dos barris para o experimento foi desenvolvido por um profissional do Município de Salinas, especializado em tanoaria. O processo iniciou-se com a aquisição de troncos de madeira, com cerca de $50 \mathrm{~cm}$ de comprimento e 18 a $22 \mathrm{~cm}$ de diâmetro. As madeiras foram 
cortadas em talisca com $45 \mathrm{~cm}$ de comprimento, $5 \mathrm{~cm}$ de largura e 1,5 cm de espessura. Antes da confecção dos barris as taliscas foram postas para secar durante 1 mês, em ambiente fechado com ventilação e iluminação natural.

Depois de secas, as taliscas, isentas de defeito, foram utilizadas para constituírem o corpo do barril em que as peças foram montadas lado a lado, tendo os anéis de ferro como base de acomodação. Depois de todas as taliscas estarem encaixadas, os espaços existentes foram preenchidos com "palha e pó de madeira" evitando que qualquer espaço tenha permanecido livre. O corpo do barril foi lixado e levado ao fogareiro, a fim de se ajustar os círculos de ferro, deixando-os totalmente ajustados à madeira.

Os tampos foram feitos com as madeiras descartadas para utilização do corpo do barril. Para a confecção dos tampos, as peças foram unidas lado a lado, fixadas com prego de duas cabeças e cortadas em formato de um círculo, com cerca de 45 $\mathrm{cm}$ de diâmetro. Assim como o corpo do barril, o tampo foi lixado para um acabamento melhor e os espaços existentes preenchidos com "palha e pó de madeira".

Após o encaixe do tampo no corpo o barril foi besuntado com uma pasta de parafina e barro e levado ao fogareiro, para ajuste dos anéis de ferro, apertando-os e vendando, eliminando todas as possíveis frestas.

\section{Armazenamento, envelhecimentoe amostragem da cachaça}

Empregaram-se, para o armazenamento, dois barris para cada madeira ensaiada. Além do armazenamento nos barris, uma amostra controle de $20 \mathrm{~L}$ de cachaça foi acondicionada em recipiente de vidro transparente, com capacidade para $25 \mathrm{~L}$, fechado com tampa do mesmo material, para permitir a comparação entre as características químicas e organolépticas das cachaças envelhecida e não-envelhecida (Tabela 1).

Tabela 1. Distribuição da cachaça nos recipientes de armazenamento

\begin{tabular}{lcc}
\hline $\begin{array}{c}\text { Recipiente de } \\
\text { armazenamento }\end{array}$ & $\begin{array}{c}\text { Quantidade de amostras } \\
\text { (unidades com 20 L) }\end{array}$ & $\begin{array}{c}\text { Quantidade total } \\
\text { em litros de cachaça }\end{array}$ \\
Amburana & 2 & 40 \\
Bálsamo & 2 & 40 \\
Ipê & 2 & 40 \\
Jatobá & 2 & 40 \\
Jequitibá & 2 & 40 \\
Carvalho & 2 & 40 \\
Vidro & 1 & 20 \\
\hline Total & 13 & 260 \\
\hline
\end{tabular}

Para o envelhecimento as amostras foram armazenadas a temperatura de 18 a $23^{\circ} \mathrm{C}$ e umidade relativa de 53 a $81 \%$, sob pouca iluminação e ventilação natural, durante seis meses (novembro de 2008 a maio de 2009).

Para avaliar a qualidade das madeiras ensaiadas quanto às características químicas e organolépticas da cachaça, retiraramse amostras de $1 \mathrm{~L}$ de cada recipiente, após 2, 4 e 6 meses de armazenamento.

\section{Características físico-químicas das cachaças}

A avaliação das características físico-químicas, amostras de cachaça foram enviadas ao Laboratório de Análises Físico-
Químicas do Microbiotec Save, localizado no Núcleo Bandeirante, em Brasília, DF, e analisadas de acordo com os métodos recomendados pelo Ministério da Agricultura (Brasil, 1986), usados para a análise de bebidas destiladas a serem engarrafadas e comercializadas no Brasil e no Exterior.

A cachaça armazenada em recipiente de vidro e as envelhecidas em barris de madeira foram analisadas em função dos teores de acidez total, fixa e volátil, álcool metílico, álcool superior, aldeídos, cobre, éster, extrato seco a $100^{\circ} \mathrm{C}$, furfural e grau alcoólico real.

\section{Características organolépticas da cachaça}

Decorridos seis meses de armazenamento (envelhecimento) as amostras de cachaça foram avaliadas sensorialmente em função do aroma, sabor, cor e impressão global, por meio de um questionário.

Para a avaliação sensorial da cachaça utilizou-se uma equipe composta de 30 provadores voluntários aos quais foram oferecidas amostras de cachaça mantida a temperatura ambiente, em copos transparentes, codificados e cobertos com vidro de relógio, que eram retirados apenas no momento da degustação.

Para as avaliações do aroma e sabor os participantes foram vendados para que a coloração não influenciasse nos julgamentos dos atributos; no teste de impressão global a venda foi retirada.

\section{RESULTADOS E DISCUSSÃO}

\section{Características químicas das cachaças}

Os valores médios da caracterização química obtidos das cachaças após serem completados dois, quatro e seis meses de armazenamento (de janeiro ao final de maio de 2009) nas madeiras de amburana, bálsamo, ipê, jatobá, jequitibá e carvalho, em comparação com a cachaça não-envelhecida, armazenada em frasco de vidro, se encontram nas Tabelas 2, 3 e 4, respectivamente.

De maneira geral observa-se que, ao final dos 180 dias, a cachaça armazenada no recipiente de vidro apresentou a mesma composição química inicial (Tabelas 2 e 3), com exceção da concentração de ésteres, que aumentou cerca de $40 \%$ durante o período de armazenamento, em virtude das reações de esterificação, que ocorrem entre compostos ácidos e álcoois do próprio destilado (Miranda et al., 2008; Alcarde et al., 2010); essas reações também ocorrem em bebidas armazenadas em recipientes inertes, porém de forma mais lenta, uma vez que não há participação das reações intrínsecas ao processo de envelhecimento em madeira (Mori et al., 2003; Alcarde et al., 2010).

Quanto às cachaças armazenadas em barris de madeira notase que, em geral, seu grau alcoólico apresentou tendência de aumento ao longo do período de envelhecimento, o mesmo ocorrendo com a acidez volátil, com o extrato seco, com os álcoois superiores, com os ésteres, aldeídos e furfural, cujas concentrações aumentaram com o avanço do período de envelhecimento; no entanto, a concentração de metanol não sofreu variação significativa ao longo dos 180 dias enquanto o teor de cobre das aguardentes apresentou ligeiro declínio com 
Tabela 2. Valores médios dos parâmetros anal isados após dois meses de armazenamento

\begin{tabular}{|c|c|c|c|c|c|c|c|}
\hline \multirow{2}{*}{ Parâmetros avaliados } & \multirow{2}{*}{$\begin{array}{l}\text { Amostra controle } \\
\text { (Vidro) }\end{array}$} & \multicolumn{6}{|c|}{ Madeira utilizada na confecção dos barris } \\
\hline & & Amburana & Bálsamo & Ipê & Jatobá & Jequitibá & Carvalho \\
\hline Acidez volátil (g $\left.100 \mathrm{~mL}^{-1}\right)$ & 0,076 & 0,086 & 0,041 & 0,112 & 0,224 & 0,410 & 0,309 \\
\hline Álcool metílico $\left(\mathrm{m} \mathrm{100mL}^{-1}\right)$ & 0,453 & 0,217 & 0,226 & 0,420 & 0,326 & 0,690 & 0,695 \\
\hline Álcool superior $\left({\left.\mathrm{m} 100 \mathrm{~mL}^{-1}\right)}^{-1}\right.$ & 0,291 & 0,019 & 0,152 & 0,302 & 0,235 & 0,327 & 0,338 \\
\hline Aldeído $\left({\left.\mathrm{g} 100 \mathrm{~mL}^{-1}\right)}^{-1}\right.$ & 0,015 & 0,023 & 0,011 & 0,421 & 0,152 & 0,110 & 0,021 \\
\hline Cobre $\left(\mathrm{mg} \mathrm{L}^{-1}\right)$ & 0,181 & 0,171 & 0,095 & 0,178 & 0,160 & 0,150 & 0,198 \\
\hline Éster $\left(\mathrm{g} 100 \mathrm{~mL}^{-1}\right)$ & 0,122 & 0,179 & 0,115 & 0,384 & 0,153 & 0,160 & 0,131 \\
\hline Extrato seco $\left(\mathrm{g} \mathrm{L}^{-1}\right)$ & 0,101 & 0,017 & 0,259 & 0,350 & 0,459 & 0,753 & 0,906 \\
\hline Furfural $\left({\left.\mathrm{g} 100 \mathrm{~mL}^{-1}\right)}^{-1}\right.$ & 0,018 & 0,017 & 0,017 & 0,054 & 0,300 & 0,075 & 0,066 \\
\hline Grau alcoólico (으) & 43,680 & 46,280 & 44,820 & 44,000 & 43,000 & 42,990 & 44,000 \\
\hline
\end{tabular}

Tabela 3. Valores médios dos parâmetros analisados após quatro meses de armazenamento

\begin{tabular}{|c|c|c|c|c|c|c|c|}
\hline \multirow{2}{*}{ Parâmetros avaliados } & \multirow{2}{*}{$\begin{array}{l}\text { Amostra controle } \\
\text { (Vidro) }\end{array}$} & \multicolumn{6}{|c|}{ Madeira utilizada na confecção dos barris } \\
\hline & & Amburana & Bálsamo & Ipê & Jatobá & Jequitibá & Carvalho \\
\hline Acidez volátil (g 100 $\mathrm{mL}^{-1}$ ) & 0,076 & 0,119 & 0,050 & 0,252 & 0,310 & 0,499 & 0,388 \\
\hline Álcool metílico $\left(\mathrm{mL} 100 \mathrm{~mL}^{-1}\right)$ & 0,423 & 0,220 & 0,237 & 0,419 & 0,179 & 0,685 & 0,693 \\
\hline 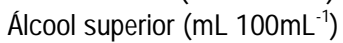 & 0,272 & 0,106 & 0,117 & 0,300 & 0,185 & 0,313 & 0,305 \\
\hline Aldeído (g $\left.100 \mathrm{~mL}^{-1}\right)$ & 0,016 & 0,049 & 0,012 & 0,446 & 0,206 & 0,020 & 0,029 \\
\hline Cobre $\left(\mathrm{mg}^{-\mathrm{L}^{-1}}\right)$ & 0,182 & 0,018 & 0,026 & 0,163 & 0,351 & 0,043 & 0,187 \\
\hline Éster $\left(\mathrm{g} 100 \mathrm{~mL}^{-1}\right)$ & 0,150 & 0,176 & 0,121 & 0,186 & 0,099 & 0,165 & 0,129 \\
\hline Extrato seco $\left(\mathrm{g} \mathrm{L}^{-1}\right)$ & 0,100 & 0,286 & 0,385 & 0,688 & 0,643 & 1,009 & 1,256 \\
\hline Furfural $\left({\left.\mathrm{g} 100 \mathrm{~mL}^{-1}\right)}^{-1}\right.$ & 0,017 & 0,017 & 0,019 & 0,125 & 0,429 & 0,087 & 0,071 \\
\hline Grau alcoólico (은) & 43,690 & 47,300 & 47,390 & 45,360 & 41,220 & 42,840 & 44,000 \\
\hline
\end{tabular}

Tabela 4. Valores médios dos parâmetros analisados após seis meses de armazenamento

\begin{tabular}{|c|c|c|c|c|c|c|c|}
\hline \multirow{2}{*}{ Parâmetros avaliados } & \multirow{2}{*}{$\begin{array}{l}\text { Amostra controle } \\
\text { (Vidro) }\end{array}$} & \multicolumn{6}{|c|}{ Madeira utilizada na confecção dos barris } \\
\hline & & Amburana & Bálsamo & Ipê & Jatobá & Jequitibá & Carvalho \\
\hline Acidez volátil (g 100 $\mathrm{mL}^{-1}$ ) & 0,0780 & 0,183 & 0,060 & 0,255 & 0,337 & 0,650 & 0,578 \\
\hline Álcool metílico $\left(\mathrm{mL} 100 \mathrm{~mL}^{-1}\right)$ & 0,4210 & 0,210 & 0,219 & 0,423 & 0,166 & 0,693 & 0,694 \\
\hline Álcool superior $\left(\mathrm{mL} 100 \mathrm{~mL}^{-1}\right)$ & 0,2540 & 0,120 & 0,136 & 0,307 & 0,198 & 0,312 & 0,309 \\
\hline Aldeído (g $\left.100 \mathrm{~mL}^{-1}\right)$ & 0,0167 & 0,053 & 0,015 & 0,316 & 0,302 & 0,024 & 0,022 \\
\hline Cobre $\left(\mathrm{mg} \mathrm{L}^{-1}\right)$ & 0,1800 & 0,000 & 0,000 & 0,122 & 0,462 & 0,058 & 0,186 \\
\hline Éster $\left(\mathrm{g} 100 \mathrm{~mL}^{-1}\right)$ & 0,1680 & 0,173 & 0,111 & 0,156 & 0,105 & 0,168 & 0,139 \\
\hline Extrato seco $\left(\mathrm{g} \mathrm{L}^{-1}\right)$ & 0,1000 & 0,300 & 0,451 & 0,756 & 0,770 & 1,429 & 1,526 \\
\hline Furfural $\left(\mathrm{g} 100 \mathrm{~mL}^{-1}\right)$ & 0,0170 & 0,015 & 0,021 & 0,250 & 0,521 & 0,962 & 0,948 \\
\hline Grau alcoólico (으) & 43,8300 & 48,130 & 47,890 & 46,900 & 40,380 & 43,450 & 44,280 \\
\hline
\end{tabular}

o envelhecimento do destilado (Tabelas 2, 3 e 4), estando em conformidade com os valores obtidos por Miranda et al. (2008), Parazzi et al. (2008) e Alcarde et al. (2010).

O grau alcoólico das cachaças armazenadas em tonéis de madeira pode sofrer oscilações em função da umidade relativa e da temperatura ambiente. No Brasil são comuns perdas de água e de álcool de 3 a $4 \%$ ao ano, seja pela qualidade dos tonéis utilizados ou pela idade das madeiras em uso. Em ambiente de baixa umidade relativa a perda de água é favorecida enquanto a alta umidade favorece a perda de álcool através dos tonéis (Nicol et al., 2003). No presente estudo os resultados obtidos ao longo das três avaliações realizadas no período de 180 dias de envelhecimento, mostraram tendência de aumento do grau alcoólico da bebida, mostrando que a evaporação de água do destilado foi maior que a de etanol durante este período, pois o armazenamento ocorreu no Planalto Central do Brasil, local de umidades relativas baixas.

Durante o período de armazenamento das cachaças, como mostrado nas Tabelas 2, 3 e 4, a acidez volátil aumentou progressivamente. Este aumento ocorreu, provavelmente, em função das reações de oxidação do etanol, o que contribuiu para a formação de acetaldeído e conduziu à formação de ácido acético (Reazin, 1981; Litchev, 1989). Além disso, alguns compostos oriundos da madeira, como ácidos orgânicos nãovoláteis, componentes secundários, como taninos e compostos fenólicos, favorecem o aumento da acidez da cachaça em envelhecimento (Mori et al., 2003; Miranda et al., 2008).

Observou-se, ao final dos seis meses de armazenamento, maior concentração de ésteres, pois, além das reações de esterificação entre os alcoóis e os ácidos da bebida, os ésteres são os principais compostos extraídos da madeira, pelos destilados (Miranda et al., 2008; Parazzi et al., 2008). Essas substâncias são produzidas durante a fermentação pelas leveduras e também durante o envelhecimento, pela esterificação de ácidos graxos, sendo o acetato de etila o componente majoritário deste grupo (Faria et al., 2003) e responsável pelo odor agradável das bebidas envelhecidas (Litchev, 1989). A concentração de ésteres praticamente triplicou durante o período de envelhecimento.

Em todas as amostras se observa que o teor de aldeídos aumentou ao longo dos 180 dias de envelhecimento do destilado. Dentre as reações químicas mais importantes durante a maturação e que altera os componentes da bebida, se destacam a oxidação e a formação de acetal. Exemplos de oxidação são a 
formação de acetaldeído e ácido acético a partir do álcool etílico (Reazin, 1981) e a formação de dimetilsulfóxido, a partir de dimetilsulfeto (Piggott \& Conner, 2003). Os equilíbrios entre acetal e acetaldeído, são estabelecidos também para muitos aldeídos e são particularmente importantes para um aroma específico, pois aldeídos têm, frequentemente, odor desagradável e pungente enquanto os acetais são agradáveis e frutados (Piggott \& Conner, 2003).

O acetaldeído tem características de odor reportadas como "refrescante", "frutado" e "verde", contribuindo para o aroma final da aguardente, tanto pela redução do odor pungente desse aldeído majoritário na bebida quanto pelo provimento das características de aroma citadas (Nóbrega, 2003). O equilíbrio entre aldeídos livres, hemiacetal e acetal, é influenciado pelo pH e pela concentração de álcool etílico (Piggott \& Conner, 2003) e também pelo tipo de madeira do tonel.

O teor de furfural também aumentou durante o envelhecimento em função provavelmente, da degradação de pentoses da madeira dos barris, conforme citado por Egorov \& Rodopulo (1994). A Instrução Normativa n. 13, de 30 de junho de 2005 (Brasil, 2005) considera separadamente furfural e hidroximetilfurfural, mas mantém o teor máximo conjunto de 5 mg. $100 \mathrm{~mL}^{-1}$ de álcool etanol anidro. No processo de produção esses compostos são formados, sobretudo durante a destilação surgindo, predominantemente, como produto de cauda em alambiques, dependendo do tipo de aquecimento (Faria et al., 2003).

Houve um acréscimo médio na concentração de álcoois superiores ao longo do experimento. Os álcoois superiores são produtos metabólicos decorrentes do crescimento das leveduras e do aproveitamento de aminoácidos como fonte de nutrientes amoniacais. Sua formação é também influenciada pelas condições do meio de fermentação, da quantidade e viabilidade do inóculo, da temperatura e do teor alcoólico final. Dependendo do equipamento e do processo de destilação, o teor no produto final pode variar bastante, tendendo a aumentar em até oito vezes o seu teor no destilado, em comparação com o do vinho (Léauté, 1990).

O álcool metílico em destilados tem origem na hidrólise de matérias pécticas. Como o teor de matérias pécticas em canade-açúcar é baixo, o teor de álcool metílico em seus destilados também é sempre baixo. O teor de cobre da aguardente diminuiu durante o período de envelhecimento, estando em conformidade com o observado por Miranda et al. (2008) e Parazzi et al. (2008).
O teor de extrato seco da aguardente aumentou com o período de envelhecimento, durante o qual o aumento do teor de extrato seco na cachaça ocorre em função da degradação da lignina pelo etanol em compostos aromáticos, como a vanilina, siringaldeído, coniferaldeído e sinapaldeído. Além da extração desses compostos pelo álcool etílico, ocorrem, ainda, alterações na lignina em virtude de oxidações e etanólise, as quais determinam denominações, como "vanila", "adocicado" e "amadeirado" no destilado (Piggott \& Conner, 2003).

Especificamente, ao se comparar os valores obtidos após os seis meses de armazenamento (envelhecimento) nas madeiras de amburana, bálsamo, ipê, jatobá e jequitibá com os valores da cachaça armazenada (envelhecida) na madeira de carvalho e com os padrões de qualidade estabelecidos pela Instrução Normativa n. 13, de 30 de junho de 2005 (Tabela 5), observa-se que o armazenamento (envelhecimento) em barris confeccionados com as madeiras ensaiadas alterou a composição química da cachaça.

Obviamente, cada madeira tem particularidade para o armazenamento de bebidas alcoólicas, porém em todos os casos a cachaça se manteve dentro dos padrões de qualidade estabelecidos pela legislação nacional em vigor (Brasil, 2005). Observa-se ainda que após os 180 dias de armazenamento as cachaças apresentaram, em geral, maiores concentrações de acidez volátil, ésteres, aldeídos, furfural, álcoois superiores e extrato seco; já as concentrações de etanol e de metanol não foram alteradas e o teor de cobre apresentou ligeiro declínio, estando em acordo com o observado por Miranda et al. (2008) e Parazzi et al. (2008) e Alcarde et al. (2010).

\section{Características organolépticas da cachaça}

As análises sensoriais indicaram a preferência, pelos consumidores, quanto aos aspectos referentes a aroma, coloração e sabor das cachaças. Os testes afetivos são utilizados quando se necessita conhecer o quanto o consumidor gosta ou não de um produto, por meio da aplicação de uma escala hedônica. Dos valores relativos de aceitabilidade podem inferir na preferência, ou seja, as amostras mais aceitas são as mais aceitas e vice-versa (Meilgaard et al., 1999).

Ao final dos seis meses de armazenamento (envelhecimento), a partir da degustação por parte de 30 voluntários pré-selecionados, foram preenchidos questionários, ao avaliarem o aroma, a cor e sabor das cachaças envelhecidas em barris confeccionados com as madeiras de amburana, bálsamo, ipê, jatobá e jequitibá, em relação à amostra armazenada em frasco de vidro.

Tabela 5. Comparação dos dados após seis meses do armazenamento com a Instrução N ormativa n. 13 de 30 de junho de 2005 (Brasil, 2005)

\begin{tabular}{|c|c|c|c|c|c|c|c|}
\hline \multirow{2}{*}{ Parâmetros avaliados } & \multirow{2}{*}{ Norma } & \multicolumn{6}{|c|}{ Madeira utilizada na confecção dos barris } \\
\hline & & Amburana & Bálsamo & Ipê & Jatobá & Jequitibá & Carvalho \\
\hline Acidez volátil (g 100 mL $\left.{ }^{-1}\right)$ & $<1,5$ & 0,183 & 0,060 & 0,255 & 0,337 & 0,650 & 0,578 \\
\hline Álcool Metílico (mL 100 $\left.\mathrm{mL}^{-1}\right)$ & $<2,0$ & 0,210 & 0,219 & 0,423 & 0,166 & 0,693 & 0,694 \\
\hline 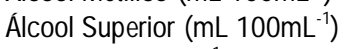 & $<0,36$ & 0,120 & 0,136 & 0,307 & 0,198 & 0,312 & 0,309 \\
\hline Aldeído (g 100mL-1) & $<0,3$ & 0,053 & 0,015 & 0,316 & 0,302 & 0,024 & 0,022 \\
\hline Cobre $\left(\mathrm{mg} \mathrm{L}^{-1}\right)$ & $<5,0$ & 0,000 & 0,000 & 0,122 & 0,462 & 0,058 & 0,186 \\
\hline Éster $\left(\mathrm{g} 100 \mathrm{~mL}^{-1}\right)$ & $<0,2$ & 0,173 & 0,111 & 0,156 & 0,105 & 0,168 & 0,139 \\
\hline Extrato seco $\left(\mathrm{g} \mathrm{L}^{-1}\right)$ & $<6,0$ & 0,300 & 0,451 & 0,756 & 0,770 & 1,429 & 1,526 \\
\hline Furfural $\left({\left.\mathrm{g} 100 \mathrm{~mL}^{-1}\right)}^{-1}\right.$ & $<5,0$ & 0,015 & 0,021 & 0,250 & 0,521 & 0,962 & 0,948 \\
\hline Grau alcoólico (은) & 38 а 48 & 48,130 & 47,890 & 46,900 & 40,380 & 43,450 & 44,280 \\
\hline
\end{tabular}


A amostra armazenada em madeira de carvalho não foi incluída na análise sensorial, subentendendo-se a preferência da maioria dos consumidores de modo geral pela mesma, tendo o objetivo apenas de se comparar a preferência das características organolépticas das demais madeiras entre si.

Quanto ao aroma, as cachaças envelhecidas nas madeiras de bálsamo e amburana obtiveram maior aceitação entre os consumidores questionados. Nas análises químicas realizadas em laboratório, observou-se que a madeira de bálsamo incorporou uma quantidade maior de extrativos à bebida, quando comparada com as demais, deixando-a com cheiro mais acentuado e agradável à grande maioria dos consumidores.

Os extrativos da madeira que passam para a cachaça durante o armazenamento (envelhecimento) trazem os componentes aromatizantes peculiares da espécie e, quanto maior a quantidade de compostos aromatizantes maior também é o aroma incorporado à bebida, pela madeira.

No quesito coloração, os valores foram semelhantes aos apresentados para o aroma, tendo a cachaça envelhecida na madeira de bálsamo maior aceitação, seguida das madeiras de amburana e ipê, com $21 \%$ cada uma, as quais apresentaram aspecto amarelado, agradando aos consumidores. Os extrativos existentes na madeira de bálsamo conferem coloração amareloavermelhado à bebida e, como a concentração desses extrativos é alta na espécie, a coloração da cachaça fica bastante acentuada.

A avaliação do sabor criou maior equidade nos resultados conferindo, às cachaças armazenadas em barris de amburana ou de bálsamo, valores praticamente iguais. A madeira de amburana, apesar de sua concentração de extrativos menor que a de bálsamo, incorpora um sabor agradável e menos adstringente à bebida.

Outro resultado interessante foi que a preferência pelos consumidores para a cachaça armazenada (envelhecida) em barris confeccionados com madeira de jequitibá e para a armazenada em vasilhame de vidro, foi praticamente a mesma, tendo a madeira de jequitibá incorporado pouco aroma e cor à cachaça.

\section{ConclusõEs}

1. A cachaça armazenada em barris confeccionados com a madeira de bálsamo (Myroxylon peruiferum) se assimilou, quanto às características químicas, à armazenada em barris de carvalho.

2. Após seis meses de armazenamento nos barris de madeira, as cachaças apresentaram maiores concentrações de acidez volátil, ésteres, aldeídos, furfural, álcoois superiores, congêneres e extrato seco.

3. As concentrações de etanol e de metanol não se alteraram e o teor de cobre apresentou ligeiro declínio com o tempo de armazenamento.

4. As características sensoriais das cachaças melhoraram com o tempo de envelhecimento, apresentando melhor aroma, sabor e mudança de coloração, quando comparadas com a armazenada em recipiente de vidro.
5. Na preferência dos degustadores voluntários selecionados, as cachaças armazenadas nas madeiras de amburana e bálsamo foram as melhores quanto às características sensoriais, pela incorporação de gosto, cor e sabor mais agradáveis.

6. Ao final do período de envelhecimento todas as cachaças avaliadas continuaram dentro dos padrões de qualidade estabelecidos pela Legislação Brasileira.

\section{LITERATURA CITADA}

ABRABE - Associação Brasileira de Bebidas. Produção de aguardente de cana. São Paulo: ABRABE, 2005. 13p.

Alcarde, A. R.; Souza, P. A.; Belluco, A. E. S. Aspectos da composição química e aceitação sensorial da aguardente de cana-de-açúcar envelhecida em tonéis de diferentes madeiras. Ciência e Tecnologia de Alimentos, v.30, p.226232, 2010.

Barboza, R. A. B.; Meneghin, M. C.; Santos, V. R,; Fonseca, S. A.; Faria, J. B. Efeito do envelhecimento na qualidade da cachaça produzida por pequenos produtores. Revista Ciência em Extensão, v.6, p. 46-56, 2010.

Brasil. Portaria n. 076 de 27 de novembro de 1986. Diário Oficial da União, Brasília, 03 de dezembro de 1986.

Brasil. Instrução Normativa n. 13 de 29 de junho de 2005. Diário Oficial da União, Brasília, 30 de junho de 2005.

Cardello, H. M. A. B.; Faria, J. B. Análise da aceitação de aguardentes de cana por testes afetivos e mapa de preferência interno. Ciência e Tecnologia Alimentar, v.33, p.27-34, 2000.

Castro Neto, J. T.; Borragini, M. C. C.; Faria, J. B. Efeito da presença de ar no envelhecimento de aguardente de cana com circulação forçada. Alimentos e Nutrição, v.16, p.239243, 2005.

Egorov, I. A.; Rodopulo, A. K. Investigation of aroma-forming substances in congnac spirits in their aging process. Applied Biochemistry and Microbiology, v.30, p.539-542, 1994.

Faria, J. B.; Cardello, H. M. A. B.; Franco, D. W.; Bôscolo, M. Influência do tipo de madeira e de tonéis para envelhecimento de aguardente de cana em sua aceitabilidade. Campinas: UNICAMP/Faculdade de Engenharia de Alimentos, 2003. 57p.

Léauté, R. Distillation in alambic. American Journal of Enology and Viticulture, v.41, p.90-103, 1990.

Litchev, V. Influence of oxidation process on the development of the taste and flavor of wine distilates. American Journal of Enology and Viticulture, v.40, p.31-35, 1989.

Meilgaard, M.; Civille, G. V.; Carr, B. T. Sensory evaluation techiniques. 3.ed. Florida: CRC Press, 1999. 354p.

Miranda, M. B.; Martins, N. G. S.; Belluco, A. E. S.; Horii, J.; Alcarde, A. R. Perfil físico-químico de aguardente durante envelhecimento em tonéis de carvalho. Ciência e Tecnologia de Alimentos, v.28, p.84-89, 2008.

Moraes, F. V. Como controlar a qualidade da cachaça. Engarrafador Moderno, v.10, p.24-29, 2001.

Mori, F. A.; Mendes, L. M.; Trugilho, P. F.; Cardoso, M. G. Utilização de eucaliptos e de madeiras nativas no armazenamento da aguardente de cana-de-açúcar. Ciência e Tecnologia de Alimentos, v.23, p.396-400, 2003. 
Nicol, D. A. Rum. In.: Lea, A. G. H.; Piggot, J. R. (ed.) Fermented beverage productions. 2. ed. New York: Klumer Academic/ Plenum Publishers, Cap.12, 2003. p.263-287.

Nóbrega, I. C. C. Análise dos compostos voláteis da aguardente de cana por concentração dinâmica do "headspace" e cromatografia gasosa-espectrometria de massas. Boletim da Sociedade Brasileira de Ciência e Tecnologia de Alimentos, v.23, p.210-216, 2003.

Padovan,F.C.; Borragini, M.C.C.; Faria, J. B. Efeito da circulaçãoda aguardente de cana no tempo de envelhecimento em ancorotes de carvalho (Quercus sp.). Alimentose Nutrição, v.15, p.267-271, 2004.
Parazzi, C.; Arthur. C. M.; Lopes, J. J. C.; Borges, M. T. M. R. Avaliação e caracterização dos principais compostos químicos da aguardente de cana-de-açúcar envelhecida em tonéis de carvalho (Quercus sp.). Ciência e Tecnologia de Alimentos, v.28, p.193-199, 2008.

Piggott, J. R.; Conner, S. P. Descriptive sensory analysis of whisky flavor. Journal Institute Brewning, v.11, p.239-262, 2003.

Reazin, G. H. Chemical mechanisms of whiskey maturation. American Journal of Enology and Viticulture, v.32, p.283289, 1981. 